\title{
Treatment of Anterior Crossbite in Skeletal Class III Malocclusion (Case Report)
}

\author{
Erna Sulistyawati \\ Department of Orthodontics \\ Faculty of Dentistry, Universitas Sumatera Utara \\ Medan, Indonesia
}

\author{
Muslim Yusuf \\ Department of Orthodontics \\ Faculty of Dentistry, Universitas Sumatera Utara \\ Medan, Indonesia
}

\author{
Syarwan \\ Resident of Orthodontics \\ Faculty of Dentistry, Universitas Sumatera Utara \\ Medan, Indonesia
}

\begin{abstract}
A female patient of 23 years old with skeletal Class III malocclusion (ANB $\mathbf{- 3}^{\circ}$ ), crossbite anterior, prognated mandible $\left(\mathrm{SNB} 90^{\circ}\right)$, proclination of upper anterior teeth (I : SN $121^{\circ}$ ), normal inclination of lower anterior teeth (I : MP 96 ${ }^{\circ}$, counter-clockwise rotation mandible (MP:SN 23 ${ }^{\circ}$ ). The patient was treated with Edgewise system by protracting upper anterior teeth and retracting lower anterior teeth. Progress treatment showed that crowded and discrepancy upper and lower anterior teeth were corrected. After 30 months, the results showed good interditation.
\end{abstract}

Keywords-skeletal class III malocclusion, crossbite anterior, prognated mandible.

\section{INTRODUCTION}

Anterior crossbite in class III skeletal malocclusion can be easily identified. This condition often found on true and pseudo claass III malocclusion. The ability to identify the type of maloclussion is needed to determine the treatment plan and to achieve a stable treatment result $[1,2]$. Some of the examination is needed to establish the diagnosis, such as history taking, skeletal, dental and soft tissue examination etc [1].

Factors that cause anterior crossbite in class III malocclusion such as herediter, upper and lower non ideal inclination relation, maxillary constriction and traumatic occlusion [1,3]. Furthermore, abnormal maxilla development results in maxilla movement forbidden by mandible and adenoid gland enlargement [7].

Functional examination was one of the way that can be used to diagnose the skeletal class III maloclussion. The prognosis was said to be good when the mandible can move backward until upper and lower incisor inclination becomes edge to edge $[1,4]$.

Early malocclusion class III treatment such as orthopaedic, oral surgery and camouflage was needed to prevent the malocclusion from worsening [2].

This case report is aimed to describe the orthodontic treatment on class III skeletal malocclusion with anterior crossbite.

\section{CASE REPORT}

A 23 years old patient came to RSGMP Orthodontic clinic on FKG USU with crowded, lower anterior teeth position in front of the upper anterior teeth (anterior crossbite). Extraoral examination revealed a concave facial profile (Figure 1)

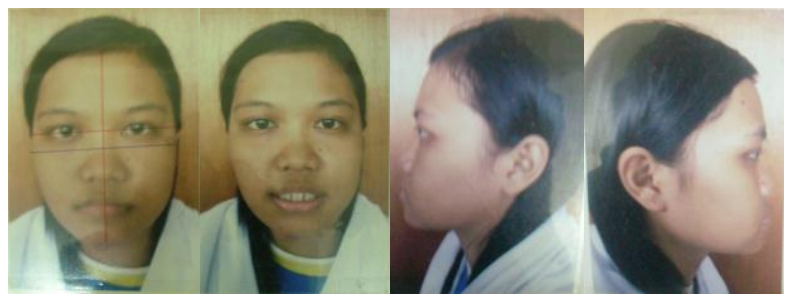

Figure 1. Pretreatment facial photos.

Intraoral examination showed poor oral hygiene, poor gingival condition without tooth mobility. Gingivitis in region $17,16,15,14,47,46,45,44,43$, 42, 41, 31, 32, 33, 34 with 36 missing. Median line shifted to right about $1 \mathrm{~mm}$ in the mandible. Diastema on 31-32, 41-42, whereas 38,48 agenesis. Class 1 Molar and canine relation on right and left region, but class III centric occlusion, crossbite on 12,11,21,22 with overjet $-3 \mathrm{~mm}$, overbite $-5 \mathrm{~mm}$, normal curve of Spee (Figure 2). Edge to edge can be achieved by patient during centric occlusion. The cephalometric analysis revealed class III skeletal malrelation and bimaxillary prognathism. Skeletal and soft tissue profile were concave. Counterclockwise mandible rotation, proclination of upper incisor, normal inclination of lower incisor (Figure 3 ). Functional analysis showed mandible distortion on left side when closing the mandible. Premature contact was found between 11, 41 and 21, 31. Panoramic radiograph examination showed 38, 48 agenesis (Figure 4)

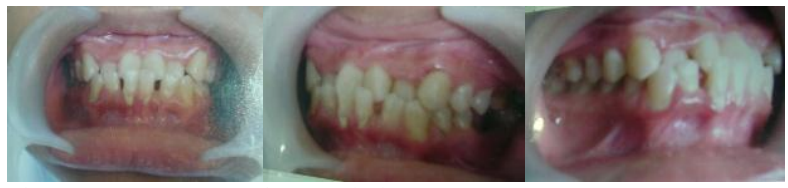

Figure 2. Pretreatment intraoral photos. 


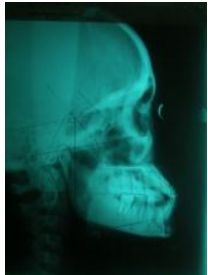

Figure 3. Pretreatment cephalometric radiograph

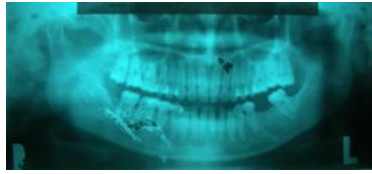

Figure 4. Pretreatment panoramic radiograph.

The purpose of this treatment was to correct the anterior crossbite with upper teeth protraction and lower teeth retraction to acquired a normal overbite and overjet, and to correct the interdigiation.

\section{CASE MANAGEMENT}

Management of this case on maxilla (nonextraction) was using fixed standard edgewise technique with minimum anchorage. The procedure was done with band 16, 26 + bracket slot 0.018 levelling and alignment AW $\varnothing 0,016$ SS multiloop + stop (Figure 5).

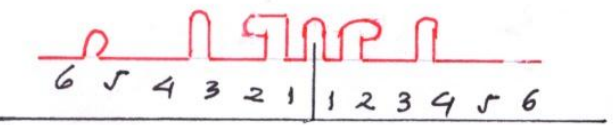

Figure 5. Band 16, $26+$ bracket slot 0.018 levelling and alignment AW Ø 0,016 SS multiloop + stop.

Protraction of upper anterior was done according to Figure 6 with interdigitation setting AW $\varnothing 0.016 \mathrm{x}$ 0,022 ss plain, artistic positioning AW $\varnothing 0,016 \times 0,025$ $\mathrm{ss}+1^{\text {st }}, 2^{\text {nd }} \& \mathrm{OB}$, and wrap around retainer.

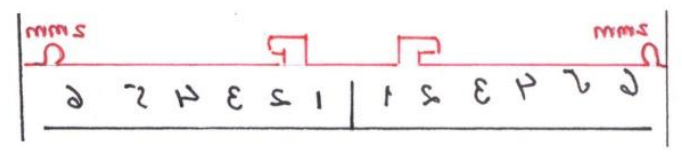

(6) (4) $32=1 / 12(3)(4) \times 6$

Figure 6. Protraction of upper anterior.

Management on mandible (non-extraction) was using fixed standard edgewise technique with moderate anchorage. The procedure was done with band 46, $37+$ bracket Slot 0,018 SS multiloop + stop and leveling and alignment AW $\varnothing 0,016$ SS multiloop. Step down performed if needed (Figure 7)

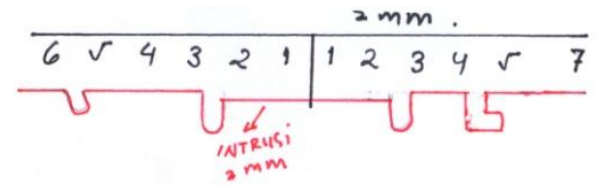

Figure 7. Band 46, 37 + bracket Slot 0,018 SS multiloop + stop and leveling and alignment AW $\varnothing 0,016$ SS multiloop.
Anterior teeth intrusion was done using AW $\varnothing 0,16$ SS + continous ligating 35-34-33, 45-44-43 and AW $\varnothing$ 0.16 SS plain + stop (Figure 8).

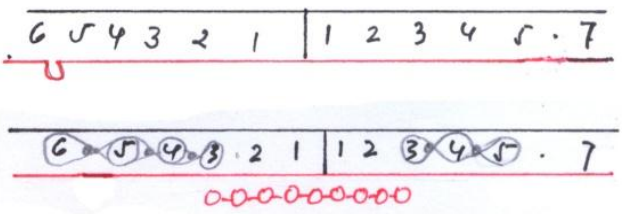

Figure 8. Anterior teeth intrusion.

Clossing space of anterior teeth was done with AW $\varnothing 0,016$ SS plain dengan power chain + continous ligating 37- 35-34-33, 43-44-45-46. Anterior teeth retraction was done with AW $\varnothing 0,016 \times 0,022$ SS plain with Clossing loop + continous ligating 37-35-34-33, 43-44-45-46 (Figure 9), plain, artistic positioning AW $\emptyset 0,017 \times 0,0251^{\text {st }}, 2^{\text {nd }} \mathrm{OB}$, and retainer wrap around

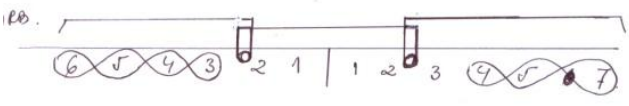

Figure 9. Clossing space of anterior teeth.

Orthodontic treatment using a fixed orthodontic appliances with standard bracket slot 0.018. Treatment started by applying the band on regio 16,26,37,46. Leveling and aligning maxilla and mandible teeth using archwire 0.014 SS vertical multiloop, followed by 0.016 SS plain for maxilla and mandible. In the next visit, diastema closure, intrusion, and anterior lower teeth retraction has been perfomed using the archwire $0.016 \mathrm{x}$ $0.022 \mathrm{SS}$ vertical helical closing loop $1 \mathrm{~mm}$ from the bracket slot to cervical. For the maxilla, protraction with open coil spring using archwire 0.016 ss has been performed gradually (Figure 10). In the first step, open coil spring has been done on the left regio 23-11 and then followed by right regio 23-11, other than that also correcting the rotation 11,21. Anchorage on regio $16,15,14,13,26,25,24,23$, continous ligating on maxilla and mandible on $37,35,34,33,46,45,44,43$. After the correction of crossbite, plain 0.016 SS was applied again, and then set the interdigitation archwire $0.016 \mathrm{X}$ 0.022 SS plain and $0.017 \times 0.025$ SS artistic positioning. The interdigitation setting assisted by using vertical elastic up and down.

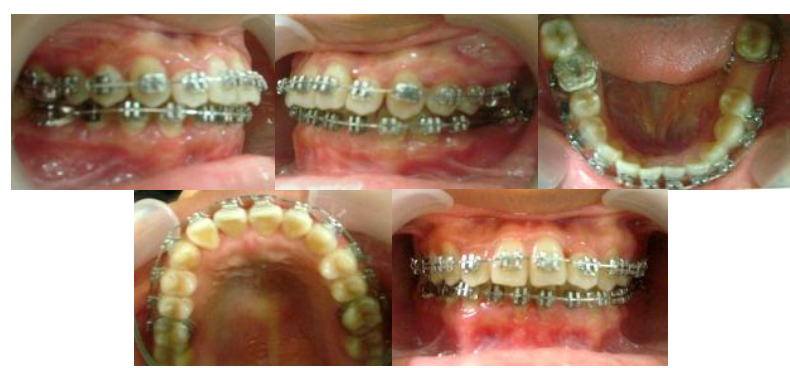

Figure 10. Intraoral photo during treatment.

After treatment has been performed for 30 months, SNB decrease by $2^{\circ}$ from $90^{\circ}$ to $88^{\circ}$. Other skeletal 
measurement tends to be stable with no significant changes (MP:SN, NS-Gn,Sgo:NME). In dental measurement such as incisor inclination which increase from $119^{\circ}$ to $122^{\circ}\left(\mathrm{N}: 120^{\circ}\right)$. Lip soft tissue position change (E-LS,E-LI plane), upper lip protraction increase from $0 \mathrm{~mm}$ to $1,5 \mathrm{~mm}$, lower lip retrusion from $3,5 \mathrm{~mm}$ to $2 \mathrm{~mm}(\mathrm{~N}: 2)$ (Figure 11,12). Furthermore, overjet and overbite return to normal (Figure 13,14,15 and Table I).

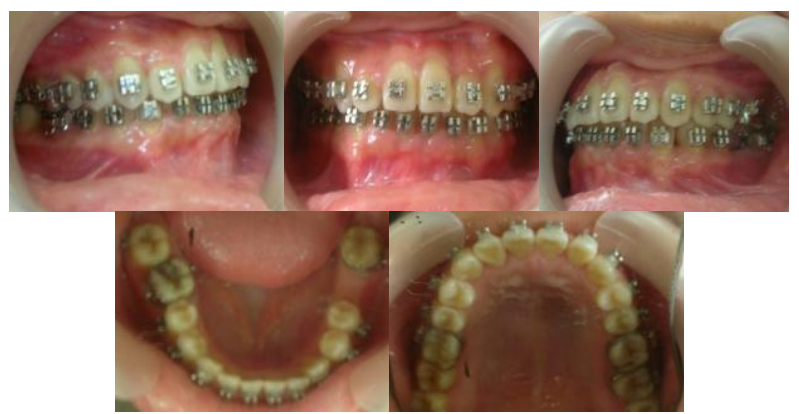

Figure 11. Intraoral photo of 30 months after treatment.

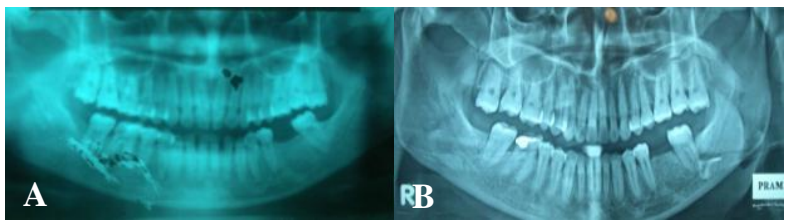

Figure 12. (A) Panoramic pretreatment and (B) panoramic post treatment.

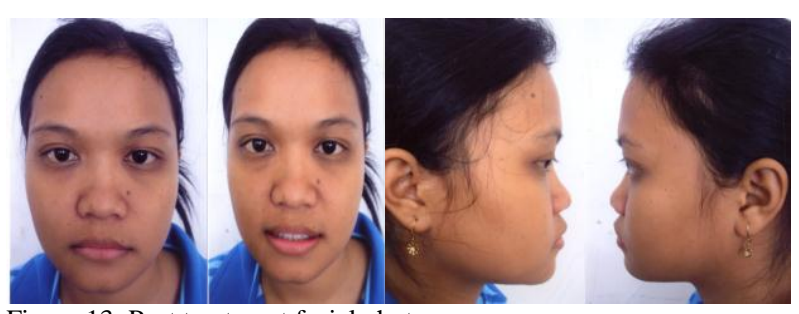

Figure 13. Post treatment facial photos.

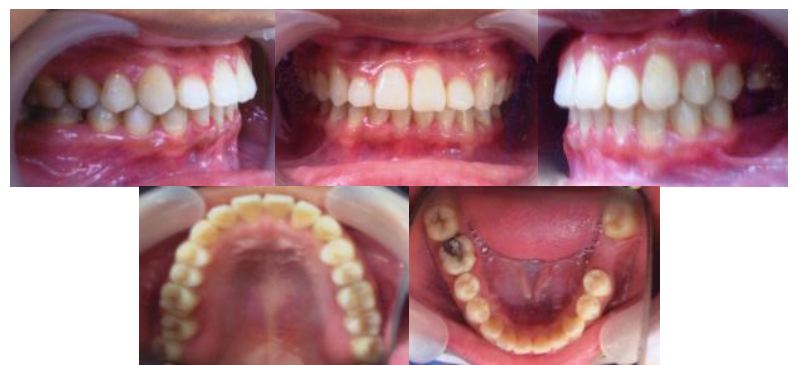

Figure 14. Post treatment intraoral photos.

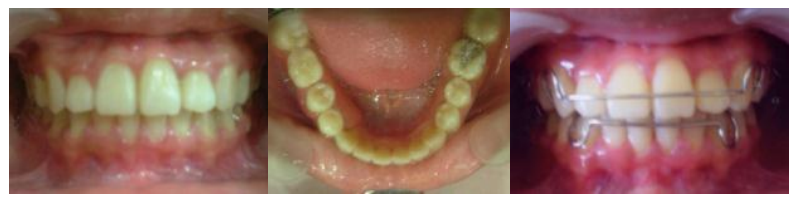

Figure 15. Intraoral applied retainer.
TABLE I. CEPHALOMETRIC PRE AND POST 30 MONTHS TREATMENT

\begin{tabular}{|c|c|c|c|c|}
\hline Measurement & $\underset{\text { Mean }}{\mathrm{X}}$ & SD & $\begin{array}{l}23^{\text {rd }} \text { August } \\
2006\end{array}$ & $\begin{array}{c}8^{\text {th }} \text { February } \\
2009\end{array}$ \\
\hline $\mathrm{SNA}^{0}$ & $84^{0}$ & 4 & $87^{0}$ & $87^{0}$ \\
\hline $\mathrm{SNB}^{0}$ & $82^{0}$ & 4 & $90^{0}>$ & $88^{0}>$ \\
\hline $\mathrm{ANB}^{0}$ & $2^{0}$ & 2 & $-3^{0}<$ & $-1^{0}<$ \\
\hline NAPog $^{0}$ & $5^{0}$ & 5 & $-7^{0<}$ & $-6^{0}<$ \\
\hline $\mathrm{MP}: \mathrm{SN}^{0}$ & $31^{0}$ & 5 & $23^{0<}$ & $22.5^{0}<$ \\
\hline $\begin{array}{l}\mathrm{NSGn}^{0} \quad \text { (sumbu } \\
\text { Y) }\end{array}$ & $65^{0}$ & 3 & $61^{0}$ & $61^{0}$ \\
\hline Pog : NB mm & $1 \mathrm{~mm}$ & 2 & 0,5 & 0 \\
\hline SGo:NMe\% & $65 \%$ & 3 & $74.33 \%>$ & $74.13 \%>$ \\
\hline \multicolumn{5}{|l|}{ Dental } \\
\hline$\underline{I}: \bar{I}^{0}$ & $120^{\circ}$ & 8 & $119^{0}$ & $122^{0}$ \\
\hline$\underline{I}: \mathrm{SN}^{0}$ & $108^{0}$ & 8 & $121>$ & $117^{0}$ \\
\hline$\overline{\bar{I}}: \mathrm{MP}^{0}$ & $101^{0}$ & 5 & $96^{0}$ & 96 \\
\hline$\underline{I}:$ APog $\mathrm{mm}$ & $9 \mathrm{~mm}$ & 3 & $6 \mathrm{~mm}$ & 7.5 \\
\hline \multicolumn{5}{|l|}{ Soft Tissue } \\
\hline Bidang E:LS mm & $0 \mathrm{~mm}$ & 2 & $0 \mathrm{~mm}$ & $1.5 \mathrm{~mm}$ \\
\hline Bidang E:LI mm & $2 \mathrm{~mm}$ & 2 & $3.5 \mathrm{~mm}$ & $2 \mathrm{~mm}$ \\
\hline
\end{tabular}

\section{DISCUSSION}

Based on the medical history, clinical examination, cephalometry analysis and study model showed that this case was class III skeletal malocclusion with ANB -3, prognathic maxilla and mandible (SNA 87,SNB 90). Concave facial profile with lower lip position more anterior than the upper lip, on functional analysis mandible were able to perform edge to edge and therefore categorized as pseudo class III skeletal malocclusion with the good prognosis $[1,4]$.

Treatment of this class III skeletal malocclusion followed by anterior crossbite, crowded, anterior lower teeth diastema are difficult to be corrected because it involves both dental and skeletal factors. In the class III skeletal malocclusion followed by factor that worsen the anomaly, the treatment must be planned correctly, the acurrate analysis to determine was the priority stage of the treatment. Anterior crossbite correction of the crowding teeth, followed by optimal interdigitaition for the occlusion stability [5,6].

Missing lower left first molar possessed a problem for the anchorage while retracting the anterior teeth, in order to prevent the loss of anchorage, continous ligation was needed on regio 37,35,34,33 and $46,45,44,43$. After the correction of anterior crossbite, constriction occur on lower left arch so occlusion lost contact. Therefore, coordinated between maxila and mandible arch been performed with archwore $0.016 \mathrm{X}$ 0.016 SS and stop on 37,46. In anterior facial profile photos, incisor inclination looks like deep overjet (4 $\mathrm{mm}$ ), this thing could be caused by a slightly mandible arch constriction because the missing molar and the unbalanced Bolton index. Panoramic radiograph showed a periodontal tissue difference between pre and post treatment because premature contact has been corrected so the mandible is free from anterior crossbite. SNB decrease from $90^{\circ}$ to $88^{\circ}$.

Skeletal malocclusion class III treatment requires a proper diagnosis and analysis to determine the necessity of extraction. Consideration of the treatment such as availability of growth factor, amount of skeletal 
discrepancy and the dental compensation that can be perfomed, as well as the stability of treatment result are needed.

In this case, orthodontic treatment corrects the occlusion funcion by correcting the anterior teeth arrangement and maintaining posterior teeth occlusion. The outcome of this treatment was a satisfying result and the pleasant facial profile for the patient.

\section{REFERENCES}

[1] K.H. Breuning, "Correction of a class III malocclusion with over $20 \mathrm{~mm}$ of space to close in the maxilla by using miniscrews for extra anchorage," Am. J. Orthod. Dentofacial Orthop., 459$469,2008$.
[2] P.W. Dwyer, "Orthodontic and orthognathic surgical correction of a severe Class III malocclusion," Am. J. Orthod. Dentofacial Orthop., 125-132, 1998

[3] S. Sato, "Case report: development characterization of skeletal class III malocclusion," Angle Orthod., vol. 64, pp. 105-111, 1994

[4] A.B.M Rabie, et al., "Diagnostic criteria for pseudo class III malocclusion," Am. J. Orthod. Dentofacial Orthop., vol. 117 pp. 1-9, 2000.

[5] A. Carano, et al., "Treatment of skeletal open bite with a device for rapid molar intrusion; A preliminary report," Ang. Orthod, vol. 75, pp. 736-746, 2005

[6] W. Daher, et al., "Nonsurgical treatment of an adult with a class III maloccllusion," Am. J. Orthod. Dentofacial Orthop., vol. 132, pp. 243-251, 2007.

[7] S.I. Bhalajhi, Management of class III malocclution. In: S.I. Bhalajhi SI, Orthodontics: The art and science. $4^{\text {rd }}$ ed., New Delhi: Arya (MEDI) Publishing House, 2009, pp. 429-36. 